\section{Scientific journal}

\section{PHYSICAL AND MATHEMATICAL EDUCATION}

Has been issued since 2013.

Науковий журнал

ФІЗИКО-МАТЕМАТИЧНА ОСВІТА

Видається з 2013.
ISSN 2413-158X (online)

ISSN 2413-1571 (print)

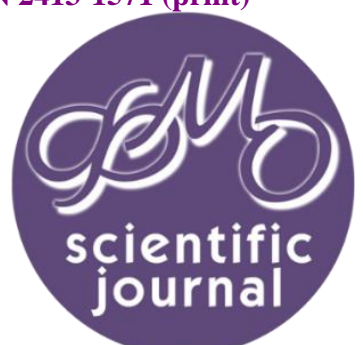

Мар'єнко М.В. Принципи, методи і підходи до формування хмаро орієнтованих систем відкритої науки у процесі навчання і професійного розвитку вчителів. Фізико-математична освіта. 2021. Випуск 1(27). С. 62-66.

Marienko M. The principles, methods and approaches to the formation of cloud-based systems of open science in the process of teaching and professional development of teachers. Physical and Mathematical Education. 2021. Issue 1(27). P. 62-66.

DOI 10.31110/2413-1571-2021-027-1-010

удк 378.046.4:: 373.58/.5.091.2.011.3-051:51]:004

М.В. Мар'єнко

Інститут інформаційних технологій і засобів навчання НАПН України, Україна popelmaya@gmail.com

ORCID: 0000-0002-8087-962X

\title{
ПРИНЦИПИ, МЕТОДИ І ПІДХОДИ ДО ФОРМУВАННЯ ХМАРО ОРІЄНТОВАНИХ СИСТЕМ ВІДКРИТОЇ НАУКИ У ПРОЦЕСІ НАВЧАННЯ І ПРОФЕСІЙНОГО РОЗВИТКУ ВЧИТЕЛІВ
}

\section{АНОТАЦІЯ}

\begin{abstract}
Формулювання проблеми. Прочес навчання та професійного розвитку вчителів можна покращити за допомогою відкритої науки, використовуючи відтворювані, прозорі та ефективні інструменти, що об'єднають дослідження та управління освітнім процесом. Тому інтеграція відкритої науки у педагогічні системи потрібна зараз як ніколи.

Матеріали і методи. Використані емпіричні (спостереження та порівняння існуючих принципів, методів і підходів до формування хмаро орієнтованих систем) методи та загальнонаукові (елементарно-теоретичний аналіз і синтез, екстраполяція, дедукція). Також було використано системно-структурний методологічний підхід.

Результати. Систематизація та узагальнення принципів, методів та підходів до формування хмаро орієнтованих систем визначених в працях науковців призвела до обгрунтування принципів, методів та підходів до формування хмаро орієнтованих систем відкритої науки. Нові принципи відкритості в науці - прозорість, доступність, авторизація та участь наукових спільнот - формують усталену відкритість у сфері педагогіки.

Висновки. Аналізуючи дослідження українських та зарубіжних дослідників виявилось, що принципи, методи та підходи до формування хмаро орієнтованих систем відкритої науки вже визначені. Однак, формування хмаро орієнтованих систем відкритої науки містить свою специріку, що полягає в сутності відкритої науки та практичному використанні її принципів.
\end{abstract}

КлЮчОВІ СЛОВА: хмаро орієнтовані системи, відкрита наука, професійний розвиток вчителів, хмаро орієнтовані системи відкритої науки, формування хмаро орієнтованих систем.

ВСТУП

Постановка проблеми. Принципи відкритої науки допоможуть ефективно подолати розрив між дослідниками та вчителями. Однак хмаро орієнтовані сервіси відкритої науки ще не набули широкого використання у навчанні та професійному розвитку вчителів. В основі розуміння відкритої науки закладено концепцію того, що дослідження повинно бути відтворюваним і прозорим, крім того воно має довгострокову цінність завдяки ефективному збереженню та обміну даними. Використання принципів відкритої науки може бути корисним для навчання та професійного розвитку вчителів для формування хмаро орієнтованих систем відкритої науки. Ефективне сприйняття принципів відкритої науки через управління даними, відтворювані дослідження та залучення зацікавлених сторін до мультимедійних додатків, можливо покращить процес навчання вчителів. Однак існують технічні, соціокультурні та інституційні проблеми сприйняття відкритої науки, включаючи практичні підходи для подолання цих перешкод у програмах підготовки та курсів підвищення кваліфікації вчителів.

Участь вчителів та учнів в процесі наукових досліджень $€$ важливим елементом у встановленні нових зв'язків між наукою та педагогічними працівниками. Тому, важливим $€$ впровадження відкритої науки, що може сприяти інноваціям з урахуванням потреб педагогів, вести до взаємного навчання та розвивати наукову культуру в усьому суспільстві в цілому. Зокрема, впровадження хмаро орієнтованих систем відкритої науки у процес навчання і професійного розвитку вчителів призведе до підвищення рівня організації дистанційного та змішаного навчання в закладах загальної середньої освіти (33CO). 
Аналіз актуальних досліджень. В. Ю. Биков та М. П. Шишкіна в своєму дослідженні (Биков\&Шишкіна, 2016) обгрунтували дві категорії принципів, згідно яких відбувається формування хмаро орієнтованого середовища: принципи відкритої освіти та специфічні принципи (характерні виключно для хмаро орієнтованих середовищ). Хоча, в даному дослідженні постає проблема обгрунтування принципів до формування хмаро орієнтованих систем відкритої науки, однак результати українських науковців В. Ю. Бикова та М.П.Шишкіної (Биков\&Шишкіна, 2016) можна взяти за основу. При цьому, частина принципів трансформується в принципи відкритої науки, а частина залишиться без змін (специфічні принципи).

У праці С. Г. Литвинової (Литвинова, 2014) розглянуті підходи, на яких базується розвиток хмаро орієнтованого навчального середовища (як класи): загальнонаукові та специфічні. Як узагальнення проведеного дослідження С. Г. Литвинова визначає авторські принципи побудови хмаро орієнтованого навчального середовища та розкриває їх зміст (Литвинова, 2014). У змісті принципів представлених С. Г. Литвиновою та принципів характерних для хмаро орієнтованих середовищ В. Ю. Бикова та М.П. Шишкіної (Биков\&Шишкіна, 2016) прослідковуються певні аналогії. Для даної роботи важливо виокремити найбільш спільні принципи у працях науковців та взяти їх за основу. 3 дослідження С. Г. Литвинової стає зрозумілим той факт, що дослідниця пов'язує методологічні підходи та принципи розвитку хмаро орієнтованого навчального середовища з основними етапами розвитку теорій: теорія розвитку навчання, теорія розвитку особистості, теорія розвитку навчального середовища та теорія розвитку хмарних обчислень (Литвинова, 2014).

Методи формування хмаро орієнтованих систем розглянула О. Д. Коротун у своєму дослідженні (Коротун, 2018). Щоправда, дослідниця їх називає характеристиками, згідно яких слід проводити формування та використання хмаро орієнтованих систем. Однак, визначені характеристики $€$ певними способами цілеспрямованого формування хмаро орієнтованої системи.

А. М. Стрюк та М. В. Рассовицька в своїй праці (Стрюк\&Рассовицька, 2014) аналізують підходи до використання хмаро орієнтованих засобів навчання та спираючись на проведений аналіз описують структуру хмаро орієнтованих засобів навчання в освітньому середовищі 3ВО. Сервісні моделі хмаро орієнтованих систем були покладені в основу розглянутих підходів (Стрюк\&Рассовицька, 2014).

У роботі О. Г. Глазунової та М. П. Шишкіної (Glazunova\&Shyshkina, 2018) визначено принципи формування хмаро орієнтованого навчально-наукового середовища, зокрема: принципи відкритої освіти, принципи відкритої науки та специфічні принципи (характерні для хмаро орієнтованих систем). Дані принципи описано та проаналізовано ї співвідношення. В рамках даного дослідження важливим $€$ співвідношення принципів відкритої науки та принципів характерних для хмаро орієнтованих систем.

У ході дослідження науковці R. Vicente-Saez, R. Gustafsson та L. Van den Brande (Vicente-Saez, Gustafsson\&Van den Brande, 2020) виявили, що відкритість у науці є багатовимірною змінною, яка варіюється щодо чотирьох вимірів або принципів: прозорість наукових результатів, доступність наукових результатів, збереження авторських прав та участь у науковому дослідженні. Кожен із принципів відкритості в науці відповідає на окреме питання стосовно відкритої науки. Нарешті, важливо зазначити, що будь-яка відкрита наукова практика охоплює чотири принципи і змінюється залежно від рівня відкритості. Ці принципи будуть покладені в основу під час формування хмаро орієнтованих систем відкритої науки у процесі навчання і професійного розвитку вчителів.

Аналізуючи останні дослідження та публікації можна зробити висновок, що принципи, методи і підходи до формування хмаро орієнтованих систем відкритої науки потребують окремого дослідження та визначення. Наявні наукові напрацювання є лише дотичними до даної проблематики. Окремі наукові здобутки можна взяти як основу для подальших наукових досліджень.

Мета статті. Обґрунтувати принципи, методи і підходи до формування хмаро орієнтованих систем відкритої науки у процесі навчання і професійного розвитку вчителів.

\section{МЕТОДИ ДОСЛІДЖЕННЯ}

В процесі дослідження були використані такі методи: емпіричні (спостереження та порівняння існуючих принципів, методів і підходів до формування хмаро орієнтованих систем); загальнонаукові (елементарно-теоретичний аналіз і синтез, екстраполяція, дедукція). Також було використано наступні методологічні підходи: системно-структурний підхід.

В статті представлені результати другого етапу (Дослідницький) виконання проєкту Національного фонду досліджень України «Хмаро орієнтовані системи відкритої науки у навчанні і професійному розвитку вчителів» (2020.02/0310) конкурсу «Підтримка досліджень провідних та молодих вчених» за 2020 р. Автор статті $є$ відповідальним виконавцем даного проєкту.

\section{РЕЗУЛЬТАТИ ДОСЛІДЖЕННЯ}

Для того, щоб обґрунтувати принципи формування хмаро орієнтованих систем відкритої науки у процесі навчання і професійного розвитку вчителів в першу чергу слід розглянути загальні принципи відкритої науки.

Згідно (Beck et al, 2020) термін «відкритість» в даному контексті означає, що будь-хто може вільно отримувати доступ, використовувати, змінювати та ділитися з будь-якою метою даними. Тоді трактуючи термін «відкрита наука» розуміємо «виконання досліджень таким чином, щоб інші дослідники (викладачі, вчителі) могли співпрацювати один з одним та робити свій внесок, де дані досліджень, лабораторні висновки та інші дослідницькі процеси є в вільному доступі, що допоможе повторно використовувати, перерозподіляти та відтворювати дослідження та його основні дані та методи» (Beck et al, 2020).

В «Дорожній карті відкритої науки LIBER» (Ayris et al, 2018) основними принципами відкритої науки, вважається відкритість, прозорість та підзвітність у всіх аспектах досліджень.

Відкрита наука означає кардинальну зміну процесів трансформації природи, науки та інновацій шляхом інтеграції IКT у процес досліджень та розвитку Інтернет-культури відкритості та обміну (Glazunova\&Shyshkina, 2018). Він $€$ більш 
відкритим, більш глобальним і загальним, більш креативним і наближеним до суспільства. Він спирається на використання електронної інфраструктури, тобто на послуги, засновані на IKT, та засоби для обробки даних та досліджень у віртуальних та спільних середовищах. Тому О.Г.Глазунова та М. П. Шишкіна окреслюють наступні принципи відкритої науки (Glazunova\&Shyshkina, 2018): принцип технологічного розвитку, принцип відкритого доступу до результатів досліджень та процесів, принцип дослідницької співпраці, що передбачає використання платформ та інфраструктур, принцип взаємодії з суспільством, принцип інноваційного характеру відкритої науки.

B праці (Beck et al, 2020) зазначено, що до принципів відкритої науки відносять: відтворюваність; прозорість експериментальних методів, спостережень та збору даних; доступність та повторне використання наукових даних; доступ громадськості та прозорість наукової роботи спілкування; використання веб-інструментів для полегшення наукової співпраці та відтворюваності.

Науковці R. Vicente-Saez, R. Gustafsson та L. Van den Brande (Vicente-Saez, Gustafsson\&Van den Brande, 2020) спроєктували концептуальну модель управління відкритою наукою та інноваціями в університетах у цифровому середовищі. Модель виділяє чотири ключові принципи відкритої науки в епоху цифрових технологій, на яких базується робота науково-дослідних груп в університетах: прозорість та доступність наукових результатів, авторизація та участь у науковому виробництві. Ці принципи лежать в основі відкритого обміну даними.

Тому згідно проведених досліджень, принципи формування хмаро орієнтованих систем відкритої науки у процесі навчання і професійного розвитку вчителів будуть розподілені як: принципи відкритої науки та загальні принципи, що стосуються усіх хмаро орієнтованих систем.

До принципів відкритої науки віднесемо:

- принцип відкритості (відкриті наукові дані, відкритий доступ до наукових досліджень та їх результатів);

- принцип прозорості (способи та методи використані в межах певного дослідження мають бути прозорими та зрозумілими, прозорими проведені всі експериментальні дослідження та зібрані дані);

- принцип доступності (всі проміжні дані, наукові здобутки мають бути доступними для подальшого використання іншими науковцями, викладачами, вчителями);

- принцип співпраці з науковими товариствами (використання спільних платформ чи хмарного інструментарію для досягнення спільних цілей, обміну досвідом між різними групами суспільства).

Аналізуючи дослідження (Биков\&Шишкіна, 2016) та (Glazunova\&Shyshkina, 2018) до загальних принципів формування хмаро орієнтованих систем віднесемо:

- принцип варіативності (наявність різноманітного інструментарію, що задовільнить потреби різних спільнот користувачів з різним рівнем знань);

- принцип індивідуалізації (забезпечення особистісно-орієнтованого підходу, налаштування інтерфейсу користувача в залежності від поставлених задач);

- принцип інтерактивності (забезпечення зворотного зв'язку та пристосування до пристроїв користувача);

- принцип надійності (забезпечення тривалого та стабільного постачання ресурсів у відповідності до запитів користувачів);

- принцип інтеграції (хмаро орієнтовані сервіси, що включені до хмаро орієнтованої системи інтегруються з іншим інструментарієм, наявність подальшої інтеграції сторонніх сервісів чи систем).

Враховуючи досвід С. Г. Литвинової (Литвинова, 2014) та специфіку хмаро орієнтованих систем відкритої науки формування подібних систем відбуватиметься згідно наступних підходів (виключно специфічні підходи):

- часовий підхід (передбачає прогнозування результатів навчання та професійного розвитку вчителів);

- інтеграційний підхід (методично виважене використання традиційних методів і форм навчання з комп'ютерно орієнтованими, використання результатів наукових досліджень в навчальних цілях);

- проєктувальний підхід (прогнозування дій та організацію навчального процесу в межах хмаро орієнтованої системи);

- науковий підхід (використання результатів наукових проєктів та взаємозв'язок зі спільнотами науковців призведе до ширшого використання академічного навчання);

- особистісно-орієнтований підхід (врахування індивідуальних особливостей усіх учасників навчального процесу).

Вивчаючи досвід О. Д. Коротун (Коротун, 2018) окреслимо такі методи для формування хмаро орієнтованих систем відкритої науки у процесі навчання і професійного розвитку вчителів:

- метод оптимізації навчання (добір мінімального інструментарію, що забезпечить розв'язання поставлених задач);

- метод використання авторських розробок (навчального матеріалу, добір різнорівневих завдань);

- метод самооцінювання (учасники навчального процесу оцінюють виконання робіт один одного);

- метод групових досліджень (із залученням спільноти науковців та їх результатів досліджень в рамках навчального процесу);

- метод змішаного навчання (поєднання та комбінування різних форм організації навчального процесу).

\section{ВИСНОВКИ ТА ПЕРСПЕКТИВИ ПОДАЛЬШОГО ДОСЛІДЖЕННЯ}

Багато відкритих наукових інструментів можуть покращити взаємозв'язки між дослідниками та вчителями, щоб викрити всі аспекти дослідницького процесу та полегшити впровадження практичних розробок в галузі освіти та педагогіки. Співпраця, можливо призведе до того, що новий програмний продукт створюватиметься шляхом обміну ідеями, щоб збалансувати потреби різних секторів та установ (навчальних та наукових). Поступове вдосконалення існуючих методик та методичних систем призведе до якісної зміни навчального процесу та професійного розвитку вчителів, що в свою чергу модернізує в шкільній практиці засоби та методи. Для вдосконалення та стандартизації педагогічних наук потрібні систематичні підходи до документування, каталогізації та обміну інформацією. Нові підходи 
також залежать від існуючих довідкових бібліотек та хмарних сервісів відкритої науки. Цілісність довідкових бібліотек значною мірою залежить від якості метаданих та документації для наданих зразків. Тому слід використовувати принципи відкритої науки для забезпечення того, щоб нові методи впроваджувались на усіх ланках освіти.

Хмаро орієнтовані системи відкритої науки спираються на відкриті наукові результати для створення інновацій у сфері педагогіки. Відкрита інноваційна практика, що базується на використанні відкритих наукових результатів для впровадження інновацій у сфері освіти за межами закладів освіти. Використання принципів відкритої науки - це великий потенціал для прискорення як внутрішньо академічних, так і зовнішніх суспільних процесів навчання та створення нових знань, пришвидшення дослідницьких та інноваційних процесів для пошуку рішень для досягнення цілей сталого розвитку та головних викликів суспільства, а також вдосконалення процесу навчання і професійного розвитку вчителів.

Аналізуючи дослідження українських та зарубіжних дослідників виявилось, що принципи, методи та підходи до формування хмаро орієнтованих систем відкритої науки вже визначені. Однак, формування хмаро орієнтованих систем відкритої науки містить свою специфіку, що полягає в сутності відкритої науки та практичному використанні їі принципів (принцип відкритості, принцип прозорості, принцип доступності, принцип співпраці з науковими товариствами).

Було визначено загальні принципи формування хмаро орієнтованих систем: принцип варіативності, принцип індивідуалізації, принцип інтерактивності, принцип надійності, принцип інтеграції.

Обґрунтовано специфічні підходи до формування хмаро орієнтованих систем відкритої науки: часовий підхід, інтеграційний підхід, проєктувальний підхід, науковий підхід, особистісно-орієнтований підхід.

Уточнено методи для формування хмаро орієнтованих систем відкритої науки у процесі навчання і професійного розвитку вчителів: метод оптимізації навчання, метод використання авторських розробок, метод самооцінювання, метод групових досліджень, метод змішаного навчання.

\section{Список використаних джерел}

1. Beck M. W.et al. 2020. The importance of open science for biological assessment of aquatic environments. PeerJ. 2020. 8:e9539. DOI : 10.7717/peerj.9539.

2. Glazunova O., Shyshkina M. The Concept, Principles of Design and Implementation of the University Cloud - based Learning and Research Environment. Proceedings of the 14th International Conference on ICT in Education, Research and Industrial Applications. Integration, Harmonization and Knowledge Transfer. Volume II: Workshops (2104), 2018. Pp. 332-347. URL : http://ceur-ws.org/Vol-2104/paper_158.pdf (Last accessed : 28.02.2020).

3. LIBER Open Science Roadmap / Ayris P. et al. Ligue des bibliothèques européennes de recherche, 2018. $29 \mathrm{p}$.

4. Vicente-Saez R., Gustafsson R., Brande L. V. (2020). The dawn of an open exploration era : Emergent principles and practices of open science and innovation of university research teams in a digital world. Technological Forecasting and Social Change. 2020. 156, 120037. DOI : 10.1016/j.techfore.2020.120037.

5. Биков В. Ю., Шишкіна М. П. Теоретико-методологічні засади формування хмаро орієнтованого середовища вищого навчального закладу. Теорія і практика управління сочіальними системами. 2016. № 2. С. 30-52.

6. Коротун О. В. Використання хмаро орієнтованого середовища у навчанні баз даних майбутніх учителів інформатики : дис. ... канд. пед. наук : 13.00.10 / Житомирський державний університет імені Івана Франка, Інститут інформаційних технологій та засобів навчання НАПН України. Київ, 2018. 356 с.

7. Литвинова С. Г. Етапи, методологічні підходи та принципи розвитку хмаро орієнтованого навчального середовища загальноосвітнього навчального закладу. Комп'ютер у школі та сім'ї. 2014. № 4. С. 5-11.

\section{References}

1. Beck, M. W et al. (2020). The importance of open science for biological assessment of aquatic environments. PeerJ, 8:e9539. DOI : 10.7717/peerj.9539 [in English].

2. Glazunova, O. \& Shyshkina, M. (2018) The Concept, Principles of Design and Implementation of the University Cloud - based Learning and Research Environment. Proceedings of the 14th International Conference on ICT in Education, Research and Industrial Applications. Integration, Harmonization and Knowledge Transfer. Volume II : Workshops (2104). (pp. 332-347). URL : http://ceur-ws.org/Vol-2104/paper_158.pdf (Last accessed : 28.02.2020) [in English].

3. Ayris, P. et al. (2018). LIBER Open Science Roadmap. Ligue des bibliothèques européennes de recherche [in English]

4. Vicente-Saez, R., Gustafsson, R., \& Brande, L. V. (2020). The dawn of an open exploration era : Emergent principles and practices of open science and innovation of university research teams in a digital world. Technological Forecasting and Social Change, 156, 120037. DOI : 10.1016/j.techfore.2020.120037 [in English].

5. Bykov, V. Yu. \& Shyshkina, M. P. (2016). Teoretyko-metodolohichni zasady formuvannia khmaro oriientovanoho seredovyshcha vyshchoho navchalnoho zakladu [Theoretical and methodological principles of forming a cloud-oriented environment of a higher educational institution]. Teoriia i praktyka upravlinnia sotsialnymy systemamy - Theory and practice of social systems management, 2, 30-52. [in Ukraine].

6. Korotun O. V. (2018). Vykorystannia khmaro oriientovanoho seredovyshcha u navchanni baz danykh maibutnikh uchyteliv informatyky [Use of the cloud-oriented environment in training of databases of future teachers of computer science]. Candidate's thesis. Kyiv : Zhytomyr State University named after Ivan Franko, Institute of Information Technologies and Learning Tools of the National Academy of Pedagogical Sciences of Ukraine [in Ukraine].

7. Lytvynova S. H. (2014). Etapy, metodolohichni pidkhody ta pryntsypy rozvytku khmaro oriientovanoho navchalnoho seredovyshcha zahalnoosvitnoho navchalnoho zakladu [Stages, methodological approaches and principles of development of cloud-oriented educational environment of general educational institution]. Kompiuter u shkoli ta simi - Computer at school and family, 4, 5-11. [in Ukraine]. 


\section{THE PRINCIPLES, METHODS AND APPROACHES TO THE FORMATION OF CLOUD-BASED SYSTEMS OF OPEN SCIENCE IN THE PROCESS OF TEACHING AND PROFESSIONAL DEVELOPMENT OF TEACHERS \\ Maiia Marienko \\ Institute of Information Technologies and Learning Tools of NAES of Ukraine, Ukraine}

Abstract. The article identifies the principles, methods and approaches to the formation of cloud-based systems of open science, in particular in the process of teaching and professional development of teachers. The principles of formation of cloud-oriented systems of open science are classified as the principles of open science and general principles that are put forward to the formation of cloud-oriented systems. Documenting and archiving the data used to create cloud-based systems also ensures that other researchers (teachers, lecturers) will be able to discover new patterns, principles and methods.

Formulation of the problem. The teaching and professional development of teachers can be improved through open science, using reproducible, transparent and effective tools that combine research and management of the learning process. Therefore, the integration of open science into pedagogical systems is needed now more than ever.

Materials and methods. Empirical (observation and comparison of existing principles, methods and approaches to the formation of cloud-oriented systems) methods and general scientific (elementary-theoretical analysis and synthesis, extrapolation, deduction) are used. The following methodological approaches were also used: system-structural approach.

Results. Systematization and generalization of principles, methods and approaches to the formation of cloud-oriented systems defined in the works of scientists has led to the substantiation of principles, methods and approaches to the formation of cloud-oriented systems of open science. New principles of openness in science - transparency, accessibility, authorization and participation of scientific communities - form an established openness in the field of pedagogy.

Conclusions. Analyzing the research of Ukrainian and foreign researchers, it turned out that the principles, methods and approaches to the formation of cloud-based systems of open science have already been defined. However, the formation of cloud-based systems of open science has its own specifics, which lies in the essence of open science and the practical application of its principles.

Key words: cloud-oriented systems, open science, professional development of teachers, cloud-oriented systems of open science, formation of cloud-oriented systems.

\section{(c) $)$ EY-NC-SA}

This work is licensed under Creative Commons Attribution-NonCommercial-ShareAlike 4.0 International License. 